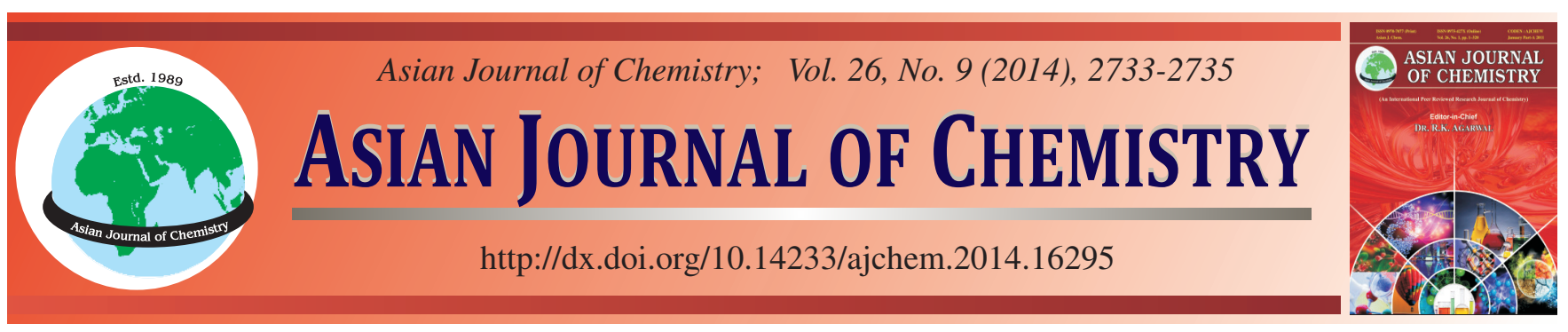

\title{
Synthesis and Characterization of Four New Chloro-Group Substituted Salamo-Type Bisoxime Compounds
}

\author{
RuO-YAn Li ${ }^{1}$, Li Jing ${ }^{2}$, JiAO-Long MenG ${ }^{3}$ and Gang Li ${ }^{3, *}$
}

${ }^{1}$ Lanzhou Huanqiu Contracting \& Engineering Company, Lanzhou 730060, P.R. China

${ }^{2}$ Petrochemical Research Center, PetroChina, Lanzhou 730060, P.R. China

${ }^{3}$ School of Chemical and Biological Engineering, Lanzhou Jiaotong University, Lanzhou 730070, P.R. China

*Corresponding author: E-mail: li_gang78@126.com

Received: 6 September 2013;

Accepted: 18 November 2013;

Published online: 28 April 2014;

AJC-15109

\begin{abstract}
A series of chloro-substituted Salamo-type bisoxime compounds 4,4',6,6'-tetrachloro-2.2'-[(1,7-heptanediyldioxy)bis(nitrilomethylidyne)] diphenol $\left(\mathrm{H}_{2} \mathrm{~L}^{1}\right), 4,4^{\prime}, 6,6$ '-tetrachloro-2.2'-[(1,8-octanediyldioxy) bis(nitrilomethylidyne)]diphenol $\left(\mathrm{H}_{2} \mathrm{~L}^{2}\right), 4,44^{\prime}, 6,6^{\prime}$-tetrachloro-2.2'-[(1,9nonanediyldioxy) bis(nitrilomethylidyne)]diphenol $\left(\mathrm{H}_{2} \mathrm{~L}^{3}\right)$ and 4,4',6,6'-tetrachloro-2.2'-[(1,10-decanediyldioxy)bis(nitrilomethylidyne)]diphenol $\left(\mathrm{H}_{2} \mathrm{~L}^{4}\right)$ have been synthesized and characterized by elemental analyses, IR spectra, UV-visible and ${ }^{1} \mathrm{H}$ NMR spectroscopy. The chloro-group substitutied salamo-type bisoxime compounds $\mathrm{H}_{2} \mathrm{~L}^{1}-\mathrm{H}_{2} \mathrm{~L}^{4}$ may be a promising units for the construction of supramolecular complexes.
\end{abstract}

Keywords: Salamo-type bisoxime compound, Synthesis.

\section{INTRODUCTION}

The favourable ligand properties of tetradentate Schiff base Salen (N,N'-bis(salicylidene)-1,2-ethylenediamine) and their derivatives have ensured continued interest in their complexes for many years ${ }^{1-5}$. Comparing the ligand properties of Salen and its oxime-based analogue Salamo, the Salamo derivatives are at least $10^{4}$ times more stable than Salen derivatives and the large electronegativity of oxygen atoms is expected to affect strongly the electronic properties of $\mathrm{N}_{2} \mathrm{O}_{2}$ coordination sphere, which can lead to different and novel properties and structures of the resulted complexes ${ }^{6-9}$. Herein, we have recently studied some novel Salen-type bisoxime chelating compounds on the basis of O-alkyloxime moiety $\left(-\mathrm{CH}=\mathrm{NO}-\left(\mathrm{CH}_{2}\right)_{\mathrm{n}}-\mathrm{O}-\right.$ $\mathrm{N}=\mathrm{CH}-)$ instead of the imine $\left(-\mathrm{CH}=\mathrm{N}-\left(\mathrm{CH}_{2}\right)_{\mathrm{n}}-\mathrm{N}=\mathrm{CH}-\right)$ group $^{10}$. Here we report the synthesis and characterization of a series of chloro-group substituted Salamo-type bisoxime compounds.

\section{EXPERIMENTAL}

3,5-Dichlorosalicylaldehyde was purchased from Alfa Aesar and used without further purification. The other reagents and solvents were analytical grade reagents from Tianjin Chemical Reagent Factory. C, H and N analyses were carried out with a GmbH VariuoEL V3 automatic elemental analyzer. IR spectra were recorded on a VERTEX70 FT-IR spectrophotometer using $\mathrm{KBr}$ pellets. UV-visible absorption spectra were recorded on a Shimadzu UV-2550 spectrometer. ${ }^{1} \mathrm{H}$ NMR spectra were recorded on a Mercury-400BB spectrometer.
Melting points were measured by the use of a microscopic melting point apparatus made in Beijing Taike Instrument Limited Company and the thermometer was uncorrected.

General procedure: Synthetic route to chloro-group substitutied Salamo-type bisoxime compounds $\mathrm{H}_{2} \mathrm{~L}^{1}-\mathrm{H}_{2} \mathrm{~L}^{4}$ are shown in Fig. 1. 1,7-bis(Aminooxy)heptane, 1,8-bis(aminooxy)octane, 1,9-bis(aminooxy)nonane and 1,10-bis(aminooxy) decane were synthesized according to an analogous method reported earlier ${ }^{10}$.

4,4',6,6'-Tetrachloro-2.2'-[(1,7-heptanediyldioxy)bis(nitrilomethylidyne)]diphenol $\left(\mathbf{H}_{2} \mathbf{L}^{1}\right)$ : To an ethanolic solution $(5 \mathrm{~mL})$ of 1,7-bis(aminooxy)heptane (146.7 mg, $1 \mathrm{mmol})$ was added an ethanolic solution $(8 \mathrm{~mL})$ of 3,5-dichloro-2hydroxybenzaldehyde $(382.2 \mathrm{mg}, 2 \mathrm{mmol})$, a pale-yellow precipitation was obtained immediately. After the solution had been stirred at $55^{\circ} \mathrm{C}$ for $4 \mathrm{~h}$, The formed precipitate was separated by filtration and washed successively with ethanol and ethanol/hexane (1:4), respectively. The product was dried under reduced pressure to obtain $338.4 \mathrm{mg}$ pale-yellow title compound $\mathrm{H}_{2} \mathrm{~L}^{1}$. Yield, $80.20 \%$. m.p. $100.0-101.0{ }^{\circ} \mathrm{C}$.

4,4',6,6'-Tetrachloro-2.2'-[(1,8-octanediyldioxy $)$ bis(nitrilomethylidyne)]diphenol $\left(\mathbf{H}_{2} \mathbf{L}^{2}\right)$ : To an ethanolic solution $(5 \mathrm{~mL})$ of 1,8-bis(aminooxy)octane (161.71 mg, $1 \mathrm{mmol}$ ) was added an ethanolic solution $(8 \mathrm{~mL})$ of 3,5-dichloro-2-hydroxybenzaldehyde (380.7 mg, $1.99 \mathrm{mmol})$, a orange mixture was obtained immediately. After the solution had been stirred at $55^{\circ} \mathrm{C}$ for $4 \mathrm{~h}$. The formed precipitate was separated by filtration 

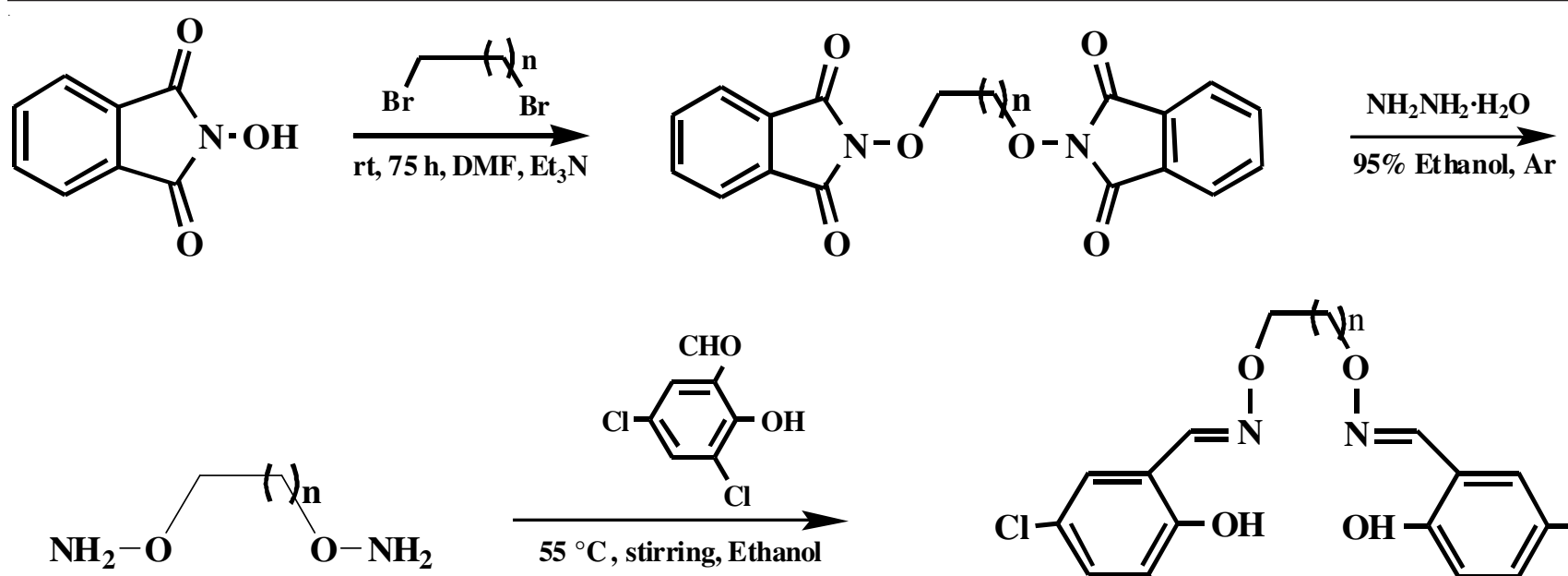

$(\mathrm{n}=6,7,8,9)$

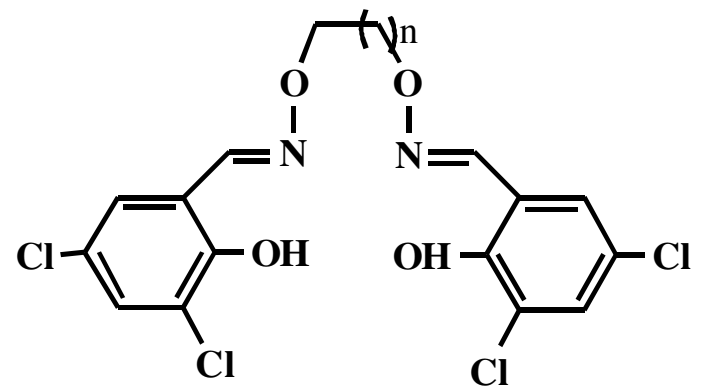

Fig. 1. Synthetic route to chloro-group substituted salamo-type bisoxime compounds $\left(\mathrm{H}_{2} \mathrm{~L}^{1}-\mathrm{H}_{2} \mathrm{~L}^{4}\right)$

and washed successively with ethanol and ethanol/hexane (1:4), respectively. The product was dried under reduced pressure to obtain $371.8 \mathrm{mg}$ yellow title compound $\mathrm{H}_{2} \mathrm{~L}^{2}$. Yield, $71.50 \%$. m.p. $110.0-111.0^{\circ} \mathrm{C}$.

4,4',6,6'-Tetrachloro-2.2'-[(1,9-nonanediyldioxy)bis (nitrilomethylidyne)]diphenol $\left(\mathbf{H}_{2} \mathbf{L}^{3}\right)$ : To an ethanolic solution $(5 \mathrm{~mL})$ of 1,9-bis(aminooxy)nonane $(51.9 \mathrm{mg}, 0.27 \mathrm{mmol})$ was added an ethanolic solution $(8 \mathrm{~mL})$ of 3,5-dichloro-2hydroxybenzaldehyde ( $104.2 \mathrm{mg}, 0.55 \mathrm{mmol})$. After the palepurple solution had been stirred at $55^{\circ} \mathrm{C}$ for $4 \mathrm{~h}$, precipitation was obtained and stirred for $6 \mathrm{~h}$. The formed precipitate was separated by filtration and washed successively with ethanol and ethanol/hexane (1:4), respectively. The product was dried under reduced pressure to obtain $105 \mathrm{mg}$ white title compound $\mathrm{H}_{2} \mathrm{~L}^{3}$. Yield, $72.80 \%$. m.p. $66.5-68.0{ }^{\circ} \mathrm{C}$.

4,4',6,6'-Tetrachloro-2.2'-[(1,10-decanediyldioxy)bis (nitrilomethylidyne) $]$ diphenol $\left(\mathbf{H}_{2} \mathbf{L}^{4}\right)$ : To an ethanolic solution ( $5 \mathrm{~mL}$ ) of 1,10-bis(aminooxy)decane (203.8 mg, $0.99 \mathrm{mmol}$ ) was added an ethanolic solution $(8 \mathrm{~mL})$ of 3,5-dichloro-2hydroxybenzaldehyde $(382.6 \mathrm{mg}, 2 \mathrm{mmol})$. The color of the mixing solution immediately turned pale-yellow and a white precipitation was obtained. After the solution had been stirred at $55{ }^{\circ} \mathrm{C}$ for $6 \mathrm{~h}$, The formed precipitate was separated by filtration and washed successively with ethanol and ethanol/ hexane (1:4), respectively. The product was dried under reduced pressure to obtain $435.2 \mathrm{mg}$ pale-yellow title compound $\mathrm{H}_{2} \mathrm{~L}^{4}$. Yield, $80.20 \%$. m.p. $91.0-91.5{ }^{\circ} \mathrm{C}$.

\section{RESULTS AND DISCUSSION}

A series of chloro-group Salamo-type bisoxime compounds $\mathrm{H}_{2} \mathrm{~L}^{1}, \mathrm{H}_{2} \mathrm{~L}^{2}, \mathrm{H}_{2} \mathrm{~L}^{3}$ and $\mathrm{H}_{2} \mathrm{~L}^{4}$ have been synthesized with high yields and the compositions are confirmed by elemental analyses, IR, UV-visible spectra and ${ }^{1} \mathrm{H}$ NMR data.

The colour, yields, melting points and elemental analytical results of the synthesized Salamo-type bisoxime compounds $\mathrm{H}_{2} \mathrm{~L}^{1}-\mathrm{H}_{2} \mathrm{~L}^{4}$ are presented in Table-1. Their compositions agree with the formulae. All the compounds are white microcrystalline solid, stable in air and soluble in hot DMF and DMSO, insoluble in methanol, ethanol, acetone, acetonitrile, chloroform, dichloromethane, tetrahydrofuran, $n$-hexane, ether and water.

IR spectra: IR spectra of the ligands $\mathrm{H}_{2} \mathrm{~L}^{1}, \mathrm{H}_{2} \mathrm{~L}^{2}, \mathrm{H}_{2} \mathrm{~L}^{3}$ and $\mathrm{H}_{2} \mathrm{~L}^{4}$ exhibit various bands from 4000 to $400 \mathrm{~cm}^{-1}$. The IR spectral details of the ligand $\mathrm{H}_{2} \mathrm{~L}^{1}, \mathrm{H}_{2} \mathrm{~L}^{2}, \mathrm{H}_{2} \mathrm{~L}^{3}$ and $\mathrm{H}_{2} \mathrm{~L}^{4}$ are given in Table-2.

TABLE-2

IR SPECTRAL DATA $\left(\mathrm{cm}^{-1}\right)$ FOR $\mathrm{H}_{2} \mathrm{~L}^{1}, \mathrm{H}_{2} \mathrm{~L}^{2}, \mathrm{H}_{2} \mathrm{~L}^{3}$ AND $\mathrm{H}_{2} \mathrm{~L}^{4}$

\begin{tabular}{ccccc}
\hline Comp. & $v(\mathrm{C}=\mathrm{N})$ & $v($ Ar-O $)$ & $v(\mathrm{O}-\mathrm{H})$ & $\begin{array}{c}v(\mathrm{C}=\mathrm{C}) \text { benzene } \\
\text { ring skeleton }\end{array}$ \\
\hline $\mathrm{H}_{2} \mathrm{~L}^{1}$ & 1607 & 1215 & 3431 & $1586,1464,1452$ \\
$\mathrm{H}_{2} \mathrm{~L}^{2}$ & 1605 & 1209 & 3431 & $1582,1447,1452$ \\
$\mathrm{H}_{2} \mathrm{~L}^{3}$ & 1607 & 1215 & 3433 & $1587,1466,1448$ \\
$\mathrm{H}_{2} \mathrm{~L}^{4}$ & 1609 & 1209 & 3432 & $1585,1463,1445$ \\
\hline
\end{tabular}

The Ar-O stretching bands occur at 1215, 1209, 1215 and $1209 \mathrm{~cm}^{-1}$ for the ligands $\mathrm{H}_{2} \mathrm{~L}^{1}-\mathrm{H}_{2} \mathrm{~L}^{4}$, respectively ${ }^{11}$. And the characteristic $\mathrm{C}=\mathrm{N}$ stretching bands of $\mathrm{H}_{2} \mathrm{~L}^{1}-\mathrm{H}_{2} \mathrm{~L}^{4}$ appear at $1609-1605 \mathrm{~cm}^{-1}$, indicating that 3,5-dichloro-2-hydroxybenzaldehyde has been condensated with 1,7-bis(aminooxy)heptane, 1,8-bis(aminooxy)octane, 1,9-bis(aminooxy)nonane and 1,10bis(aminooxy)decane, respectively and formed new Salamotype compounds ${ }^{12}$. In the $1587-1445 \mathrm{~cm}^{-1}$ region, the observed bands were attributed to aromatic $\mathrm{C}=\mathrm{C}$ vibrations. In addition,

TABLE-1

COLOUR, YIELDS, MELTING POINTS AND ANALYTICAL DATA FOR $\mathrm{H}_{2} \mathrm{~L}^{1}, \mathrm{H}_{2} \mathrm{~L}^{2}, \mathrm{H}_{2} \mathrm{~L}^{3}$ AND $\mathrm{H}_{2} \mathrm{~L}^{4}$

\begin{tabular}{cccccccc}
\hline \multirow{2}{*}{ Comp. } & \multirow{2}{*}{ Colour } & \multirow{2}{*}{ m.p. $\left({ }^{\circ} \mathrm{C}\right)$} & \multirow{2}{*}{ Yield $(\%)$} & \multirow{2}{*}{ m.f. (m.w.) } & \multicolumn{3}{c}{ Elemental analysis (\%): Found (Calcd.) } \\
\cline { 6 - 8 } & & & & $\mathrm{C}$ & $\mathrm{H}$ & $\mathrm{N}$ \\
\hline $\mathrm{H}_{2} \mathrm{~L}^{1}$ & Pale-yellow & $100-101$ & 80.20 & $\mathrm{C}_{21} \mathrm{H}_{22} \mathrm{~N}_{2} \mathrm{O}_{4} \mathrm{Cl}_{4}(508.22)$ & $49.67(49.63)$ & $4.42(4.36)$ & $5.39(5.51)$ \\
$\mathrm{H}_{2} \mathrm{~L}^{2}$ & Yellow & $110-111$ & 71.50 & $\mathrm{C}_{22} \mathrm{H}_{24} \mathrm{~N}_{2} \mathrm{O}_{4} \mathrm{Cl}_{4}(522.25)$ & $50.52(50.60)$ & $4.74(4.63)$ & $5.31(5.36)$ \\
$\mathrm{H}_{2} \mathrm{~L}^{3}$ & White & $66.5-68.0$ & 72.80 & $\mathrm{C}_{23} \mathrm{H}_{26} \mathrm{~N}_{2} \mathrm{O}_{4} \mathrm{Cl}_{4}(536.27)$ & $51.49(51.51)$ & $4.95(4.89)$ & $5.17(5.22)$ \\
$\mathrm{H}_{2} \mathrm{~L}^{4}$ & White & $91.0-91.5$ & 80.20 & $\mathrm{C}_{24} \mathrm{H}_{28} \mathrm{~N}_{2} \mathrm{O}_{4} \mathrm{Cl}_{4}(550.30)$ & $52.45(52.38)$ & $5.28(5.31)$ & $5.00(5.09)$ \\
\hline
\end{tabular}




\begin{tabular}{|c|c|}
\hline & $\begin{array}{c}\text { TABLE-4 } \\
{ }^{1} \mathrm{H} \text { NMR DATA FOR } \mathrm{H}_{2} \mathrm{~L}^{1}, \mathrm{H}_{2} \mathrm{~L}^{2}, \mathrm{H}_{2} \mathrm{~L}^{3} \text { AND } \mathrm{H}_{2} \mathrm{~L}^{4}\end{array}$ \\
\hline Comp. & ${ }^{1} \mathrm{H}$ NMR $\left(400 \mathrm{MHz}\right.$, DMSO- $\left.d_{6}, \delta \mathrm{ppm}\right)$ \\
\hline $\mathrm{H}_{2} \mathrm{~L}^{1}$ & $2.42-.50(\mathrm{~m}, 10 \mathrm{H}), 4.45(\mathrm{~s}, 4 \mathrm{H}), 7.55(\mathrm{~d}, J=2.0 \mathrm{~Hz}, 2 \mathrm{H}), 7.71(\mathrm{~d}, J=2.2 \mathrm{~Hz}, 2 \mathrm{H}), 8.45(\mathrm{~s}, 2 \mathrm{H}), 9.95(\mathrm{~s}, 2 \mathrm{H})$ \\
\hline $\mathrm{H}_{2} \mathrm{~L}^{2}$ & $2.43-.51(\mathrm{~m}, 12 \mathrm{H}), 4.45(\mathrm{~s}, 4 \mathrm{H}), 7.52(\mathrm{~d}, J=2.0 \mathrm{~Hz}, 2 \mathrm{H}), 7.72(\mathrm{~d}, J=2.2 \mathrm{~Hz}, 2 \mathrm{H}), 8.46(\mathrm{~s}, 2 \mathrm{H}), 9.85(\mathrm{~s}, 2 \mathrm{H})$ \\
\hline $\mathrm{H}_{2} \mathrm{~L}^{3}$ & $2.43-.53(\mathrm{~m}, 14 \mathrm{H}), 4.43(\mathrm{~s}, 4 \mathrm{H}), 7.52(\mathrm{~d}, J=2.0 \mathrm{~Hz}, 2 \mathrm{H}), 7.68(\mathrm{~d}, J=2.2 \mathrm{~Hz}, 2 \mathrm{H}), 8.41(\mathrm{~s}, 2 \mathrm{H}), 9.76(\mathrm{~s}, 2 \mathrm{H})$ \\
\hline $\mathrm{H}_{2} \mathrm{~L}^{4}$ & $2.40-.54(\mathrm{~m}, 16 \mathrm{H}), 4.43(\mathrm{~s}, 4 \mathrm{H}), 7.50(\mathrm{~d}, J=2.0 \mathrm{~Hz}, 2 \mathrm{H}), 7.72(\mathrm{~d}, J=2.2 \mathrm{~Hz}, 2 \mathrm{H}), 8.43(\mathrm{~s}, 2 \mathrm{H}), 9.77(\mathrm{~s}, 2 \mathrm{H})$ \\
\hline
\end{tabular}

the O-H stretching bands of the ligands at 3600-3200 $\mathrm{cm}^{-1}$ region disappear in the ligands and the strong absorption bands of the ligands appear at about $3431 \mathrm{~cm}^{-1}$, which are the evidence for the existence of hydroxyl group in ligands ${ }^{13}$. IR spectral results of the ligands further confirmed the correctness of the target ligands.

UV-Vis spectra: The UV-visible spectra of the title compounds $\mathrm{H}_{2} \mathrm{~L}^{1}-\mathrm{H}_{2} \mathrm{~L}^{4}$ in $5 \times 10^{-5}$ chloroform solution are shown in Table-3.

TABLE-3

\begin{tabular}{cccc}
\multicolumn{4}{c}{ TABLE-3 } \\
UV-VISIBLE SPECTRA DATA FOR $\mathrm{H}_{2} \mathrm{~L}^{1}, \mathrm{H}_{2} \mathrm{~L}^{2}, \mathrm{H}_{2} \mathrm{~L}^{3}$ AND $\mathrm{H}_{2} \mathrm{~L}^{4}$ \\
\hline Comp. & $\mathrm{C}\left(\times 10^{-5}\right.$ mol L $\left.{ }^{-1}\right)$ & $\begin{array}{c}\text { First band } \\
\lambda_{\max 1}(\mathrm{~nm})\end{array}$ & $\begin{array}{c}\text { Second band } \\
\lambda_{\max 2}(\mathrm{~nm})\end{array}$ \\
\hline $\mathrm{H}_{2} \mathrm{~L}^{1}$ & 5.02 & 275 & 313 \\
$\mathrm{H}_{2} \mathrm{~L}^{2}$ & 5.01 & 276 & 315 \\
$\mathrm{H}_{2} \mathrm{~L}^{3}$ & 5.03 & 278 & 318 \\
$\mathrm{H}_{2} \mathrm{~L}^{4}$ & 5.08 & 280 & 321 \\
\hline
\end{tabular}

The absorption spectra of $\mathrm{H}_{2} \mathrm{~L}^{1}-\mathrm{H}_{2} \mathrm{~L}^{4}$ have small difference. Each ligand exhibits two intense peaks at 275 and 313 $\mathrm{nm}$. The former absorption peaks can be assigned to the $\pi-\pi^{*}$ transition of the benzene rings, while the latters one can be attributed to the intra-ligand $\pi-\pi^{*}$ transition of the $\mathrm{C}=\mathrm{N}$ bonds ${ }^{13}$. It is of note that there was no absorption at $400 \mathrm{~nm}$, which is seen in the corresponding salen derivatives. The absorption is ascribed to the quinoid form of $\mathrm{H}_{2}$ salen $^{14,15}$.

${ }^{1}$ H NMR data: The ${ }^{1} \mathrm{H}$ NMR spectra of the title compounds $\mathrm{H}_{2} \mathrm{~L}^{1}-\mathrm{H}_{2} \mathrm{~L}^{4}$ in DMSO- $d_{6}$ are shown in Table-4.

The ${ }^{1} \mathrm{H}$ NMR spectra showed a singlet at about 8.41-8.46 $\mathrm{ppm}$ indicating the the existence of oxime bonds ${ }^{14}$.

\section{Conclusion}

A new series of Salamo-type compounds $\mathrm{H}_{2} \mathrm{~L}^{1}-\mathrm{H}_{2} \mathrm{~L}^{4}$ possessing two oxime bonds instead of imine bonds have been designed and synthesized by the reaction of 2 equivalents of 3,5-dichloro-2-hydroxybenzaldehyde with 1,7-bis(aminooxy)heptane, 1,8-bis(aminooxy)octane, 1,9-bis(aminooxy)nonane or 1,10-bis(aminooxy)decane under mild conditions, respectively. The Salamo-type compounds may be a promising units for the construction of supramolecular complexes.

\section{REFERENCES}

1. P.A. Vigato and S. Tamburini, Coord. Chem. Rev., 252, 1871 (2008).

2. Y. Sui, D.P. Li, C.H. Li, X.H. Zhou, T. Wu and X.Z. You, Inorg. Chem., 49, 1286 (2010).

3. C. Meermann, K.W. Törnroos and R. Anwander, Inorg. Chem., 48, 2561 (2009).

4. T.K. Saha, V. Ramkumar and D. Chakraborty, Inorg. Chem., 50, 2720 (2011).

5. R.M. Haak, A. Decortes, E.C. Escudero-Adán, M.M. Belmonte, E. Martin, J. Benet-Buchholz and A.W. Kleij, Inorg. Chem., 50, 7934 (2011).

6. S. Akine, T. Taniguchi and T. Nabeshima, Angew. Chem. Int. Ed., 41, 4670 (2002).

7. S. Akine, W.K. Dong and T. Nabeshima, Inorg. Chem., 45, 4677 (2006).

8. S. Akine, T. Tadokoro and T. Nabeshima, Inorg. Chem., 51, 11478 (2012).

9. S. Akine, S. Hotate and T. Nabeshima, J. Am. Chem. Soc., 133, 13868 (2011).

10. (a) W.K. Dong, Y.X. Sun, C.Y. Zhao, X.Y. Dong and L. Xu, Polyhedron, 29, 2087 (2010); (b) W.K. Dong, Y.X. Sun, Y.P. Zhang, L. Li, X.N. He and X.L. Tang, Inorg. Chim. Acta, 362, 117 (2009); (c) W.K. Dong, X.N. He, H.B. Yan, Z.W. Lv, X. Chen, C.Y. Zhao and X.L. Tang, Polyhedron, 28, 1419 (2009); (d) W.K. Dong, Y.X. Sun, Y.P. Zhang, L. Li, X.N. He and X.L. Tang, Inorg. Chim. Acta, 362, 117 (2009); (e) W.K. Dong, C.Y. Zhao, Y.X. Sun, X.L. Tang and X.N. He, Inorg. Chem. Commun., 12, 234 (2009); (f) W.K. Dong, Y.X. Sun, X.N. He, J.F. Tong and J.C. Wu, Spectrochim. Acta A, 76, 476 (2010); (g) W.K. Dong, L. Wang, Y.X. Sun, J.F. Tong and J.C. Wu, Chinese J. Inorg. Chem., 27, 372 (2011); (h) W.K. Dong, Y.X. Sun, S.J. Xing, Y. Wang and X.H. Gao, Z. Naturforsch., 67b, 197 (2012).; (i) W.K. Dong, Y.X. Sun, G.H. Liu, L. Li, X.Y. Dong and X.H. Gao, Z. Anorg. Allg. Chem., 638, 1370 (2012); (j) W.K. Dong, S.J. Xing, Y.X. Sun, L. Zhao, L.Q. Chai and X.H. Gao, J. Coord. Chem., 65, 1212 (2012); (k) W.K. Dong and Y.J. Ding, Cryst. Res. Technol., 43, 321 (2008).

11. S. Akine, T. Taniguchi, W. Dong, S. Masubuchi and T. Nabeshima, J. Org. Chem., 70, 1704 (2005).

12. J.A. Faniran, K.S. Patel and J.C. Bailar Jr., J. Inorg. Nucl. Chem., 36, 1547 (1974).

13. T. Ghosh, B. Mondal, T. Ghosh, M. Sutradhar, G. Mukherjee and M. Drew, Inorg. Chim. Acta, 360, 1753 (2007).

14. H.E. Smith, Chem. Rev., 83, 359 (1983).

15. S. Akine, T. Taniguchi and T. Nabeshima, Chem. Lett., 30, 682 (2001). 